M.N. Arbilei

Biomedical Engineering

Department, UOT

Baghdad, Iraq

70031@uotechnology.edu.iq

\section{Composition Design Modeling and Experimental Verification of (Co Ni Al) Shape Memory Alloys}

Abstract- The most important concepts to apply a shape memory alloy in many industrial applications is the composition design that controls the transformation temperatures. In this paper, two mathematical models were created to predict the transformation temperatures for poly-crystalline (Co-Ni$A l)$ alloys. The data that was depend on to find the relation between chemical composition and transformation temperatures were concluded from previous work and approved by preparing samples in investigation practically. Four different alloys were prepared to verify this relation. It was indicated that the best criteria that present the chemical composition is the (e/a) and make the alloy applicable for different applications. These suggested chemical compounds could be controlled and adjusted according to heat treatment time.

Keywords-SMA, Modeling, Equivalent Valance Electron

Accepted on: 11/01/2018

How to cite this article: M.N. Arbilei, "Composition Design Modeling and Experimental Verification of (Co Ni Al) Shape Memory Alloys," Engineering and Technology Journal, Vol. 36, Part A, No. 1, pp. 84-88, 2018.

\section{Introduction}

Shape memory alloys was applied in a wide range of application especially in biomedical sensors and pipe coupling as in the petroleum industries where welding is not applicable. [1,2] A wide biomedical application also needed the SMA to be designed to work in a specific temperature within the range of the application like catheterization producers. [1] Co-Ni-Al alloys highly applicable FSMA and SMAs. These alloys are cheaper than other SMAs. This come from there composition. Where, these alloys include inexpensive elements in comparison with other SMAs. In addition to that the mechanical properties of this alloy are very notable. [3,4]

The behavior of this alloy could be a normal shape memory alloy that effected by temperature to remember its shape or by magnetic field in addition to temperature according to chemical composition where the cure temperature of this alloy will fix this property. Figure 1 (A) showed that the $\mathrm{Co} \mathrm{Ni} \mathrm{Al}$ of 29\% Aluminum transformed to magnetic alloy when the Cure temperature below the transformation temperatures after increasing Cobalt atomic content more than 37\% .$[3,4]$

According to Figure (1) it was indicated that the transformation temperatures highly effected by chemical composition of $\mathrm{Co}$ and $\mathrm{Ni}$. Where, the To increase with $\mathrm{Ni}$ at.\% and decrease with Co At.\%. These effects taken place at fixed Al At.\%.

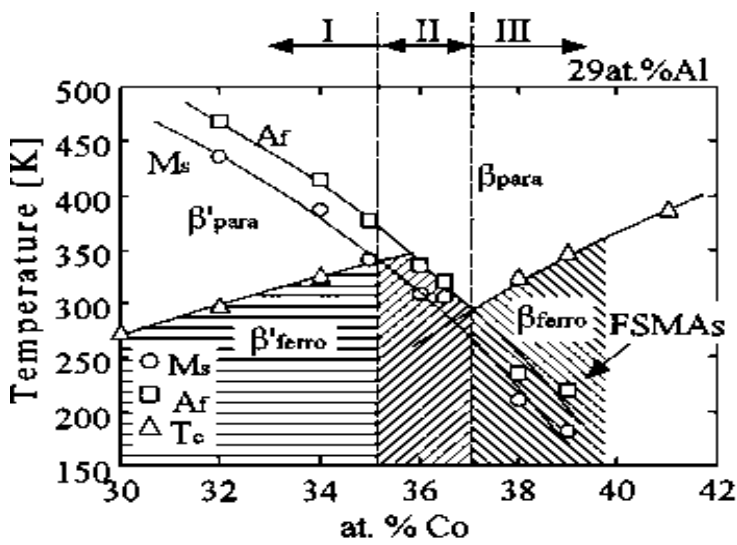

(A) Ms \& Af affacted by Co at.\% for 29 at. $\% \mathrm{Al}$

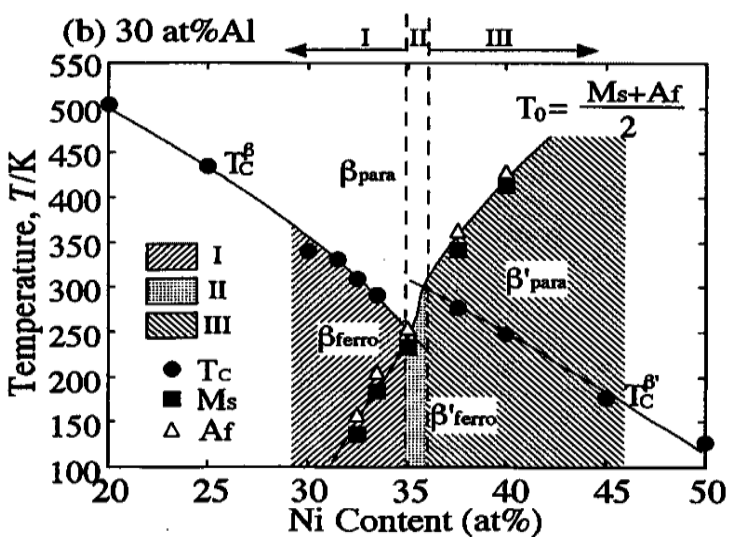

(B) Ms \& Af affacted by Ni at.\% for 30 at.\% $\mathrm{Al}$

Figure 1 Composition dependence of the Curie temperature Tc, the martensitic transformation temperature Ms and the austenitic finishing temperature Af. The FSME can be observed in the hatched region. $[3,4]$ 
The valance electron consecration factor (e/a) give an indication to the chemical composition by a group of researchers [7-10]. It was indicated that he the relation between the chemical composition and the transformations temperatures ranged from 7.587.66 and the martensitic transformation starting and austenitic ending temperatures increases in this range from $(140-260)^{\circ} \mathrm{K}$ (see Figure 2).

From Figure (2) It could be seen that the chemical composition effecting strongly on the transformation temperatures in comparison with heat treatment time. Where it could be concluded that $\mathrm{Tc}$ increases with an increase in the Co content and a decrease in the $\mathrm{Al}$ content. While, Ms decreases with an increase in both the $\mathrm{Co}$ and $\mathrm{Al}$ contents. [3,4]

The effect of e/a cannot be considered as a mathematical model because it could not be presented as a curve with a clear mathematical equation. This pushed the researches to find the criteria that put in consideration the changes in chemical composition for $\mathrm{Co}$ and $\mathrm{Ni}$ with a fixed $\mathrm{Al}$ at.\%. as shown in Figure $3[5,6]$

The main preparation procedure of this alloy has been done with two steps which are melting and heat treatment. The heat treatment variables for this alloy is by heating to a temperature that make the alloy in the area of both $(\beta+\gamma)$ area. $[3,4,6]$

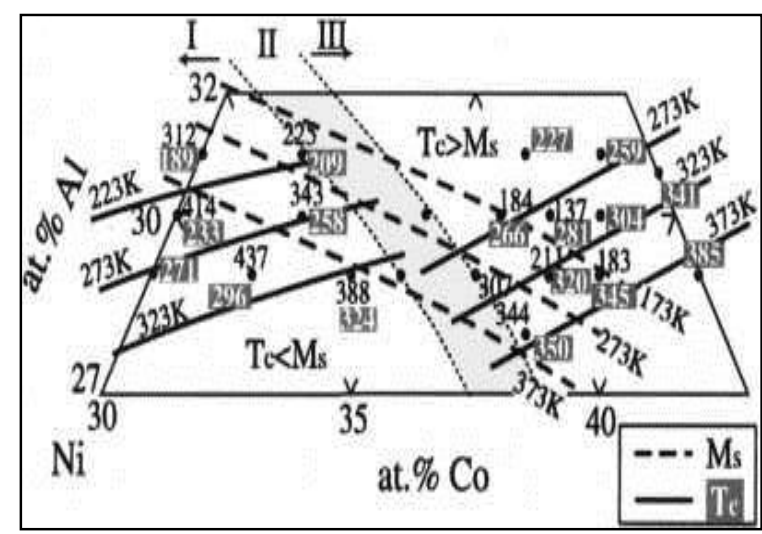

Figure 2: Composition dependence of the Curie temperature Tc and the martensitic transformation temperature Ms in the Co Ni Al ternary system. [3]
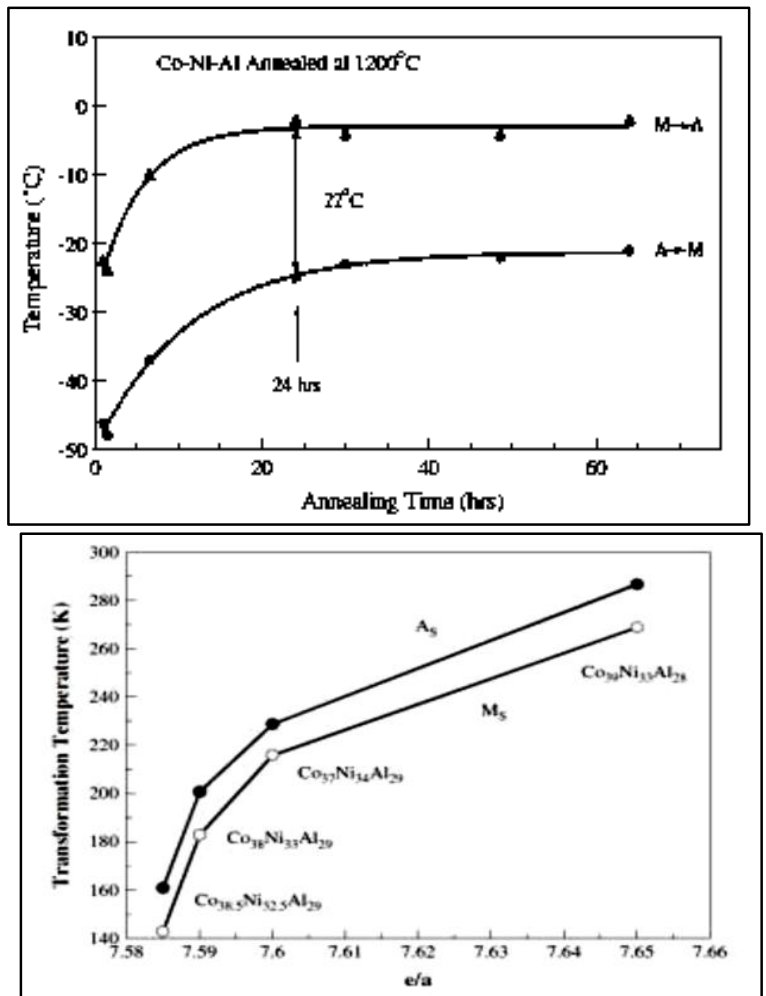

Figure 3: Valance electron concentration on starting transformation temperature for the melt-spin alloys in deferent compositions [6]

Figure 4 effect of annealing time at $1200^{\circ} \mathrm{C}$ on transformation temperatures. [9]

The heat treatment temperature was $1200{ }^{\circ} \mathrm{C}$. The time of heating was ranged from 1 to 24 hours [3,4,6-8] The researchers found that the transformation temperatures could be increased by increasing heat treatment time by 50 degrees. and further increase heat treatment time effect will be ineffective after 20 hours as shown in Figure (4). $[9,10]$

According to this figure it could be indicated that the transformation temperatures could be increased with about $25{ }^{\circ} \mathrm{C}$ in case of increasing the heat treatment time from 1 to 24 hours. [11, 12]

\section{Experimental Work}

Two main resources were selected to support our work with data. The manufacturing process of our samples are melted samples in different chemical compositions. The samples generally annealed for more than 12 hours and then quenched in ice water. As shown in Table (1). All samples have a fixed $\mathrm{Al}$ atomic content of $29 \%$. The four transformations temperatures for these alloys for the two revers transformation from $\mathrm{A}$ to $\mathrm{M}$ shown in figure with two points presenting the starting $\left(\mathrm{M}_{\mathrm{s}}\right.$ and $\left.\mathrm{A}_{\mathrm{s}}\right)$ and final transformation temperatures $\left(\mathrm{M}_{\mathrm{f}}\right.$ and $\left.\mathrm{A}_{\mathrm{f}}\right)$ have 
been presented finally with To which calculated according to Wiseman Equation $=\frac{M s+A s}{2}$

Four alloys have been prepared by mixing pure powders of the three components and the mixture finally pressed to a shape disks. These disks were melted with trips arc melting furnace under Argon to avoid oxidation. The alloys mounted in Argon gas filled tubes then heat treated for 12 hours at $1200{ }^{\circ} \mathrm{C}$ then quenched in ice water. Samples have been chemically analyzed by using EDAX by (FAI SEM). The Transformation Temperatures have been investigated by DSC Testing with (DSC 2000). All the results of DSC and e/a calculations listed in Table (1).

The e/a have been calculated by the summation of the number of free valance electrons multiplied by the element atomic content divided by the summation of the atomic weights of each component.

Many researchers prepared Co $\mathrm{Ni} \mathrm{Al}$ alloy with different chemical compositions grouped according to the $\mathrm{Al}$ at.\%. These composition with its transformation temperatures which presented as To. The transformation temperatures collected to all samples that heat treated for time to 20 hours.

Table 1: The prepared Samples DSC Results and (e/a) Calculations

\begin{tabular}{lllllllll}
\hline \hline $\mathrm{Co} \%$ & $\mathrm{Ni} \%$ & $\mathrm{Al} \%$ & $\mathrm{e} / \mathrm{a}$ & $\begin{array}{l}\mathrm{Ms} \\
{ }^{\circ} \mathrm{C}\end{array}$ & $\begin{array}{l}\mathrm{Mf} \\
{ }^{\circ} \mathrm{C}\end{array}$ & $\begin{array}{l}\mathrm{As} \\
{ }^{\circ} \mathrm{C}\end{array}$ & $\begin{array}{l}\mathrm{Af} \\
{ }^{\circ} \mathrm{C}\end{array}$ & $\begin{array}{l}\mathrm{To} \\
{ }^{\circ} \mathrm{C}\end{array}$ \\
\hline 36 & 35 & 29 & 7.61 & 65 & 47 & 65 & 101 & 83 \\
35 & 36 & 29 & 7.62 & 60 & 37 & 80 & 110 & 85 \\
34 & 37 & 29 & 7.63 & 104 & 80 & 150 & 175 & 139.5 \\
34 & 37 & 29 & 7.63 & 115 & 105 & 121 & 140 & 127.5 \\
\hline
\end{tabular}

\section{Multiple Regression and Analysis}

First group of samples was with $\mathrm{Al}$ at.\% of $29 \%$. This regression came with a linear equation taking Co at. $\%$ as a variable. The accuracy of the mathematical model indicated by calculating the errors squared root value. The accuracy of this model was about $93 \%$.

The other group of samples was with $\mathrm{Al}$ at\% of $30 \%$ gave the same type of model. These relations could not give a full picture about the chemical composition for the three elements.

According to above the (e/a) taken in mind while creating the mathematical models. And the second stage of this work. The mathematical model for e/a for both groups together give a low accuracy of $74 \%$. As shown if Figure 5.
Table 2: Collected Samples Data from previous researches. According to figures $1,2,3[3,4,6]$

\begin{tabular}{|c|c|c|c|c|}
\hline Co at. $\%$ & $\mathrm{Ni}$ at. $\%$ & $\mathrm{Al}$ at. $\%$ & e/a & To (C) \\
\hline 39 & 32 & 29 & 7.58 & -71.5 \\
\hline 38 & 33 & 29 & 7.59 & -63 \\
\hline 38 & 33 & 29 & 7.59 & -50 \\
\hline 37 & 34 & 29 & 7.6 & -34 \\
\hline 36.5 & 34.5 & 29 & 7.605 & 40.5 \\
\hline 36 & 35 & 29 & 7.61 & 49.5 \\
\hline 35 & 36 & 29 & 7.62 & 86 \\
\hline 32 & 39 & 29 & 7.65 & 177 \\
\hline 34 & 37 & 29 & 7.63 & 127 \\
\hline 35 & 36 & 29 & 7.62 & 102 \\
\hline 36 & 35 & 29 & 7.61 & 52 \\
\hline 38 & 33 & 29 & 7.59 & -48 \\
\hline 34 & 37 & 29 & 7.63 & 128.5 \\
\hline 35 & 36 & 29 & 7.62 & 135 \\
\hline 37 & 34 & 29 & 7.6 & 35 \\
\hline 39 & 32 & 29 & 7.58 & -65 \\
\hline 34 & 37 & 29 & 7.63 & 135 \\
\hline 37 & 34 & 29 & 7.6 & 35 \\
\hline 39 & 32 & 29 & 7.58 & -65 \\
\hline 32 & 39 & 29 & 7.65 & 253 \\
\hline 34 & 37 & 29 & 7.63 & 163 \\
\hline 35 & 36 & 29 & 7.62 & 118 \\
\hline 36 & 35 & 29 & 7.61 & 65.5 \\
\hline 38 & 33 & 29 & 7.59 & -9.5 \\
\hline 39 & 32 & 29 & 7.58 & -39.5 \\
\hline 38.5 & 32.5 & 29 & 7.585 & -97 \\
\hline 38 & 33 & 29 & 7.59 & -57 \\
\hline 37 & 34 & 29 & 7.6 & -24.5 \\
\hline 37 & 33 & 30 & 7.53 & -65 \\
\hline 38 & 32 & 30 & 7.52 & -122 \\
\hline 36.5 & 33.5 & 30 & 7.535 & -72 \\
\hline 35 & 35 & 30 & 7.55 & -22 \\
\hline 33 & 37 & 30 & 7.57 & 78 \\
\hline 30 & 40 & 30 & 7.6 & 153 \\
\hline
\end{tabular}

By applying the multiple regression with the two variables (e/a) and $\mathrm{Al}$ at.\%. for each groups of samples alone. The accuracy give a high results of $98 \%$ for $\mathrm{Al}$ at. $\% 30$ and $93 \%$ for $\mathrm{Al}$ at.\% of 29 each group alone. Where the mathematical models for the two groups shown below in Equations No.1 for alloys with $\mathrm{Al}$ at $\%=30 \% \&$ No.2 with $\mathrm{Al}$ at $\%=29 \%$, 
with an Accuracy of $98.22 \%$ and $92.22 \%$ respectively.

$\mathrm{To}=-26127+3459(\mathrm{e} / \mathrm{a})$

$\mathrm{To}=-31894+4197(\mathrm{e} / \mathrm{a})$

But a full one relation need to be created as shown below note that all calculation done by using Minitab Ver. 17.

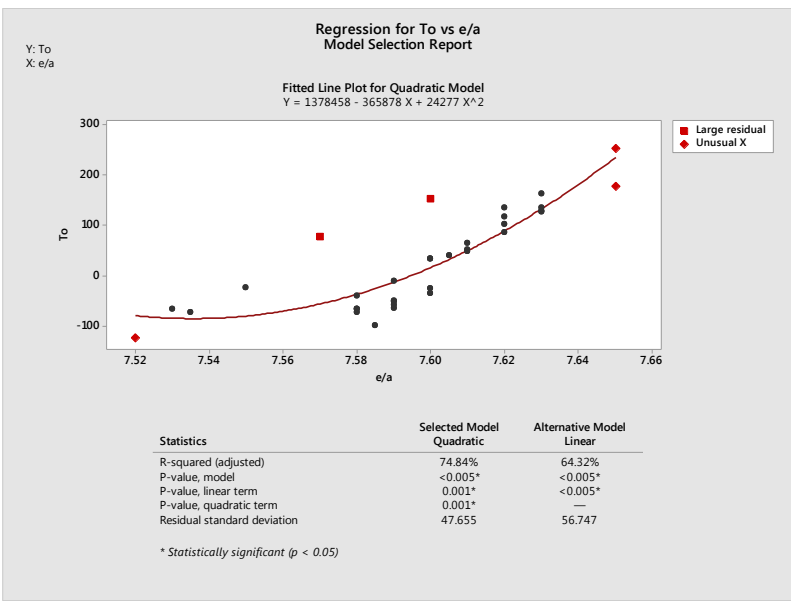

Figure 5: showing the low accuracy when the regression build on e/a ratio alone without taking the effect of $\mathrm{Al}$ at.\% in consideration.

From figure (6) is could be seen that the e/a of $\mathrm{Al}$ at.\% increasing increase the To. And the different change of e/a with $\mathrm{Al}$ content showing a different slop with two lines that can describe the low accuracy of the grouped Al Contents model where the accuracy was very low of about $76 \%$. This will show why the researcher who depend on e/a alone without taking $\mathrm{Al}$ content in consideration could not conclude a mathematical model.

Figure (7) explain the dependence of the R-squared values on the $\mathrm{Al}$ and e/a. the $\mathrm{Al}$ showed a high dependency more that e/a. and showing the enhancement in accuracy after adding $\mathrm{Al}$ content to the model which increased to $95 \%$.

The Total Model for both groups of $\mathrm{Al}$ at.\% final mathematical model for this work is presented in equation no. 3 below:

$\mathrm{To}=-228792+29523(\mathrm{e} / \mathrm{a})+6756(\mathrm{Al} \%)-869(\mathrm{e} / \mathrm{a})$ (Al\%)

Testing Models showed that the calculated To from the suppurated groups for the experimental alloys more accurate and near to the investigated temperatures as presented in Table 3. These alloys laid in both magnetic and non-magnetics shape memory alloy area in the equilibrium diagrams shown in Figure 1.

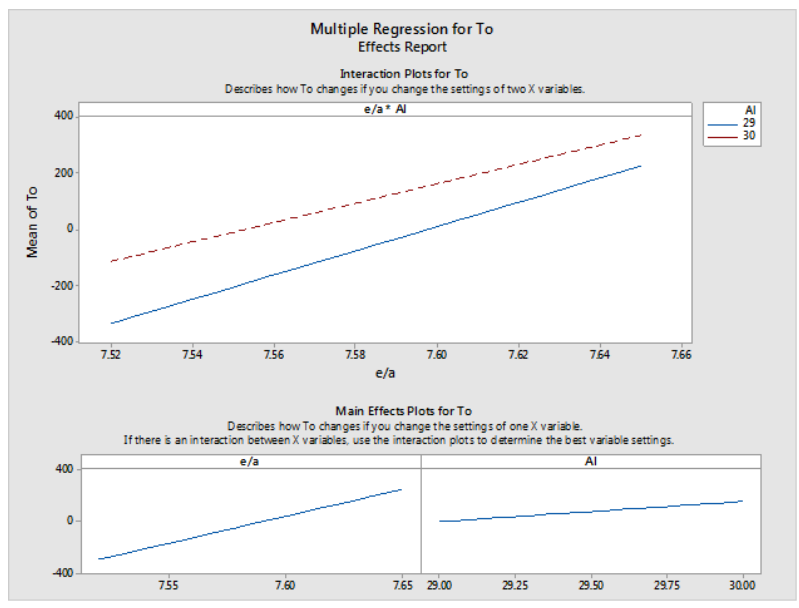

Figure 6: Showing the effect of Al Content and (e/a) ratio on To

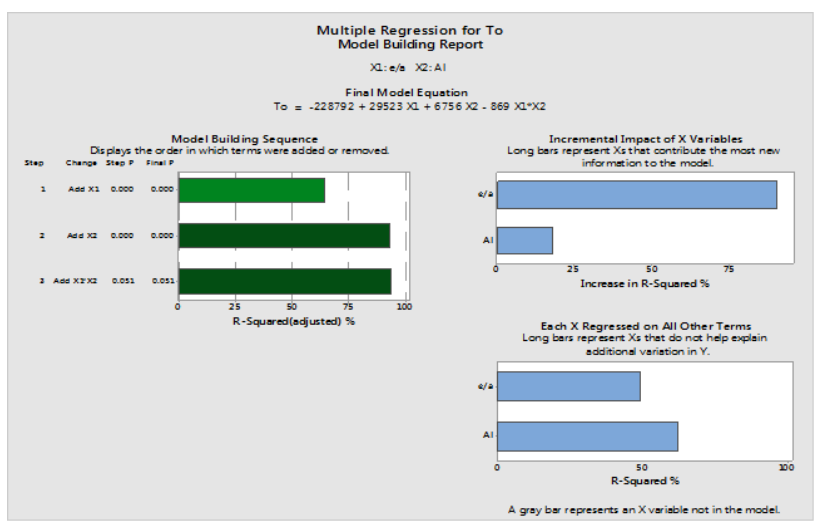

Figure 7: Showing the accuracy change when the model takes both e/a and $\mathrm{Al}$ at $\%$ as multiple variable in the equation.

Table 3: Compression between the real and calculated results for the two models.

\begin{tabular}{lllllll}
\hline \hline Co \% & Ni \% & Al \% & e/a & Exp. & Eq.1 & Eq.2 \\
\hline 36 & 35 & 29 & 7.61 & 83 & 45.17 & 22.42 \\
35 & 36 & 29 & 7.62 & 85 & 87.14 & 65.64 \\
34 & 37 & 29 & 7.63 & 139.5 & 129.11 & 108.86 \\
34 & 37 & 29 & 7.63 & 127.5 & 129.11 & 108.86 \\
\hline
\end{tabular}

According to that it could be proved that this mathematical model could be applied not only for the magnetics shape memory alloys region. [10]

According to that this alloy should be treated as groups according to the $\mathrm{Al}$ at $\%$ even in mathematical modeling.

\section{Conclusion}

1- The best way to design $\mathrm{Co} \mathrm{Ni} \mathrm{Al}$ alloys and compare between compositions is by fixing $\mathrm{Al}$ Content and change between $\mathrm{Ni}$ and $\mathrm{Co}$.

2- The (e/a) electron valance ratio is not enough alone but the $\mathrm{Al}$ at.\% need to be considered as a 
criteria that could be depend on to design the chemical composition according to the transformations temperatures ranges needed for the application.

3- The heat treatment time can control and finally tune the transformation temperatures.

4- The relation could cover both $\mathrm{Co} \mathrm{Ni} \mathrm{Al}$ behavior as a magnetics and nonmagnetic shape memory alloy.

5- The best range to make the alloy applicable in biomedical sensing application or pipe coupling is between (7.605-7.610) with $\mathrm{Al}$ atomic of $29 \%$ this transformation temperature could be adjusted more by changing treatment time.

\section{Acknowledgments}

1- Department of Materials Engineering and the University of Technology for their labs help.

2- Royal Hashemite Society, Jordan for helping in DSC investigations

\section{References}

[1] Lorenza Petrini and Francesco Migliavacca, "Biomedical Applications of Shape Memory Alloys", Hindawi Publishing Corporation, Journal of Metallurgy, Volume 2011, Article ID 501483, 15 pages, 2011.

[2] K.K. Jee, J. H. Han, "Suggestion of pipe coupling method for maximum and uniform joining stresses", Materials Transactions, Vol. 47, No. 3, 2006.

[3] K. Oikawa, T. Ota, F. Gejima, T. Ohmori, "Phase Equilibria and Phase Transformations in new B2-type Ferromagnetic Shape Memory Alloys of Co-Ni-Ga and Co-Ni-Al Systems", Materials Transections Vol. 42 No.11 PP 2472-2475, 2001.

[4] K. Oikawa, L. Wulff, T. Iijima, F. Gejima, T. Ohmori, "Promising ferromagnetic $\mathrm{Ni}-\mathrm{Co}-\mathrm{Al}$ shape memory alloy system", Applied Physics Letters VOL. 79, No. 20,PP. 3290-3292, 2001.

[5] G.P. Tiwari, R.V. Ramanujan, "Review the Relation Between the Electron to Atom Ratio and Some Properties of Metallic Systems", Journal of Materials Science Vol. 36, PP. 271-283, 2001.

[6] Y. Tanaka et al, "Ferromagnetic Co-Ni-Al Shape Memory Alloys with $(\beta+\gamma)$ Two-Phase Structure", Materials Transactions, Vol. 45, No. 2, PP. 427-430, 2004.

[7] C. Efstathiou a, H. Sehitoglu a,*, A.J. Wagoner Johnson a, R.F. Hamilton a,H.J. Maier b, Y. Chumlyakov c, "Large reduction in critical stress in $\mathrm{Co}-\mathrm{Ni}-\mathrm{Al}$ upon repeated transformation", Scripta Materialia, No.51, PP. 979-985, 2004.

[8] R.F. Hamilton a, H. Sehitoglu a, *, C. Efstathiou a, H.J. Maier b,Y. Chumlyakov c, X.Y. Zhang a, "Transformation of $\mathrm{Co}-\mathrm{Ni}-\mathrm{Al}$ single crystals in tension", Scripta Materialia, No. 53 , PP.131-136, 2005.

[9] Y. Tanaka, K. Oikawa, Y. Sutou, T. Omori, R. Kainuma, K. Ishida, "Martensitic transition and superelasticity of $\mathrm{Co}-\mathrm{Ni}-\mathrm{Al}$ ferromagnetic shape memory alloys with + two-phase structure", Materials Science and Engineering A 438-440 , 1054-1060, 2006.

[10] M. N. Arbilei, "Improvement of Co Ni Al MSMA alloy to be used in biomedical applications" $\mathrm{PhD}$ theses submitted to the department materials engineering university of technology. Iraq, Baghdad 2014 .

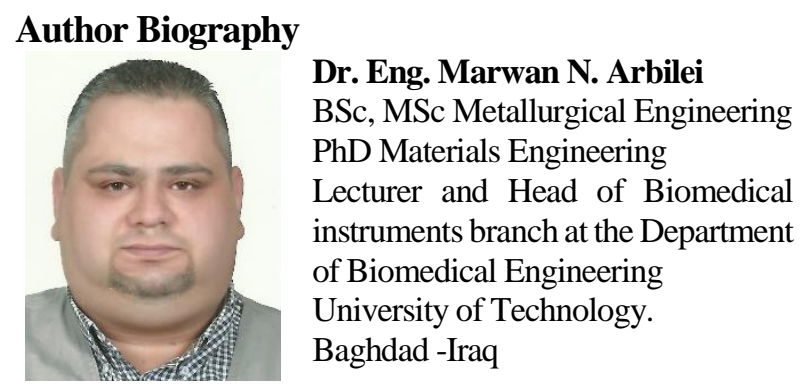

Marwan Nafea Ali, Member at the Iraqi Engineers Society since 1997, MSc degree in 2000. Worked as an academic staff member at the department of production engineering and Metallurgy, UOT from 2002. In 2014 Marwan Arbilei got his $\mathrm{PhD}$ degree in Materials Engineering in the field of application SMA in Biomedical Application. 